\title{
Biotechnological

\section{Assessment of location of anterior ethmoidal artery using cone beam computed tomography (CBCT)}

\author{
Shima Javdan ${ }^{1}$, Roshanak Ghaffari ${ }^{*}$ and Saeed Sohilipour ${ }^{3}$ \\ ${ }^{1}$ Postgraduate Student, Department of Oral Radiology, Dental School, Islamic Azad University, Isfahan \\ Khorasgan Branch Isfahan Iran \\ ${ }^{2}$ Department of Oral and Maxillofacial Radiology, Dental Faculty, Isfahan Khorasgan Branch, Islamic Azad \\ University \\ ${ }^{3}$ Otolaryngology, Isfahan University of Medical Sciences, Isfahan, Iran
}

\begin{abstract}
Anterior ethmoidal artery (AEA) is an important landmark, which may be accidentally injured or traumatized during surgical procedures. This study aimed to determine the position of AEA on CBCTscans. In this descriptive analytical study, CBCT scans of 129 patients evaluated. The mean distance from AEA to anterior base of the skull, posterior frontal sinus wall, nasion, anterior nasal spine (ANS), orbital roof, inferior turbinate and the mean angle between AEA and ANS were evaluated using SIDEXIS 3D software. Independent and paired t-test and Fisher's test were used for statistical analyses with $\mathrm{P}<0.05$ level of significance. The mean distance from AEA was $11.60 \pm 1.94 \mathrm{~mm}$ to orbital roof, $32.66 \pm 4.33 \mathrm{~mm}$ to inferior turbinate, $8.96 \pm 4.51$ to posterior wall of the frontal sinus, $2.09 \pm 2.18 \mathrm{~mm}$ to the anterior base of the skull, $18.01 \pm 3.90 \mathrm{~mm}$ to the nasion and $58.69 \pm 4.24 \mathrm{~mm}$ to the ANS. The angle between AEA and NS was $55.15 \pm 4.36^{\circ}$. The distances from AEA to orbital roof, inferior turbinate, nasion and ANS in men were significantly greater than those in women $(\mathrm{P}<0.05)$. nasion. $(\alpha=0 / 05)$ Surgical procedures in areas close to AEA are high-risk. Determination of the position of AEA prior to endoscopic surgery of the sinus is highly important. CBCT can help determine the location of AEA prior to surgery to prevent unwanted surgical complications.
\end{abstract}

KEY WORDS: CONE-BEAM COMPUTED TOMOGRAPHY; ETHMOID; ARTERY

ARTICLE INFORMATION:

${ }^{*}$ Corresponding Author: Roshanak Ghaffari

Received $23^{\text {rd }}$ June, 2017

Accepted after revision $26^{\text {th }}$ Sep, 2017

BBRC Print ISSN: 0974-6455

Online ISSN: 2321-4007 CODEN: USA BBRCBA

a Thomson Reuters ISI ESC and Crossref Indexed Journal

NAAS Journal Score 2017: 4.31 Cosmos IF: 4.006

- A Society of Science and Nature Publication, 2017. All rights reserved.

Online Contents Available at: http//www.bbrc.in/

DOI: $10.21786 / \mathrm{bbrc} / 10.3 / 33$ 


\section{INTRODUCTION}

Inflammatory diseases of paranasal sinuses are a common serious problem. In the recent decades, functional endoscopic sinus surgery (FESS) has revolutionized surgical treatment of paranasal sinuses. In this technique, due to the proximity of paranasal sinuses to some important structures such as anterior base of skull, orbit and ethmoidal artery, unintentional injury to these anatomical structures may cause serious complications (Basak et al. 1998). Anterior ethmoidal artery (AEA) is an important landmark, which may be accidentally traumatized or injured during surgical procedure of anterior ethmoidal sinus. Injury to AEA may cause severe nasal bleeding, intra-orbital hemorrhage, posterior orbital hematoma, spinal fluid leak and intracranial bleeding in rare cases (Ding et al. 2012 Eren et al. 2016).

In FESS, superior lateral border of AEA and its inferior border in contact with inferior turbinate are marked (Rontal et al. 1991). The distance between AEA and the contact area with the inferior turbinate outlines the safe area for surgical manipulation. Since in FESS the width of ethmoid forceps is maximally $10 \mathrm{~mm}$ when opened, the surgeon must have adequate knowledge about the space limitations in this area (Rontal et al. 1991; Basak et al. 1998). Knowledge about the anatomical location of AEA and its detection on images can help prevent unwanted complications during surgery (Ding et al. 2012). AEA is among the most important reference landmarks for endoscopic surgery since it determines the posterior location of recess. Its detection in frontoethmoidal suture determines the location of anterior base of skull (Monjas-Cánovas et al. 2012; Ko et al. 2014).

Ethmoidal artery originates from the orbital artery. Some branches of ethmoidal artery originate from supraclinoid portion of the internal carotid artery and pass through the optical foramen towards the orbit in a lateral position. In coronal plane, a conical groove in the medial orbital wall may be seen, which indicates the exit point of ethmoidal artery between the superior oblique muscle and medial rectus muscle. It indicates anterior ethmoidal foramen and can serve as a reference anatomical landmark to determine the location of AEA (Monjas-Cánovas et al. 2012). The location of AEA relative to the ethmoidal air cells may be variable but it is often located between the second and third lamellae next to basal lamella (Ding et al. 2012).

Ko et al, in 2014 evaluated the efficacy of AEA to determine the location of frontal sinus in endoscopic sinus surgery using computed tomography (CT) and offered a classification for the position of AE. Guldner et al. provided a similar classification in 2012 using CBCT (Guldner et al. 2012). At present, CBCT is increasingly used for implant imaging and endodontic treatments and is a new technique in ENT for assessment of sinuses. It is superior to CT since it has lower cost and lower patient radiation dose compared to CT. Studies on determination of location of AEA using CBCT are limited. Thus, this study has aimed to determine the position of AEA on CBCT scans.

\section{MATERIALS AND METHODS}

This descriptive analytical study was conducted on 129 CBCT scans of patients (70 females and 59 males) over 18 years of age presenting to the Oral and Maxillofacial Radiology Department of Isfahan University of Medical Sciences, School of Dentistry. All CBCT scans had been taken with one CBCT unit (Galileos-Sirona Bensheim, Germany) with the exposure settings of $85 \mathrm{kVp}$ and 21-35 mAs (depending on the patient's weight). The inclusion criterion was age over 18 years. The exclusion criteria were history of surgery or trauma to paranasal sinuses and skull base, congenital facial anomalies, malignancies or lesions causing opacity of frontal recess and anterior ethmoidal cells. Multiplanar (coronal, sagittal and oblique sagittal) reconstructed images were assessed using SIDEXIS 3D software. Next, notch in the medial orbital wall and bony sulcus of lateral wall of the olfactory fossa (anterior ethmoidal sulcus) on coronal sections which indicate the anterior ethmoidal foramen were used for detection of the AEA (Figure 1).

Due to the presence of variations in the path of artery, distance from the artery to the base of skull was measured. In type I, the entry point of AEA is adjacent to the anterior base of the skull. In type II, it has less than $1 \mathrm{~mm}$ distance from the base of the skull. In type III, AEA has a distance equal or more than $1 \mathrm{~mm}$ from the anterior base of the skull (Guldner et al. 2012) (Figure 2). To determine the position of AEA relative to the frontal sinus in the sagittal plane, distance from the AEA to the posterior wall of the frontal sinus was measured (Monjas-Cánovas et al. 2011) (Figure 3). Distance from the AEA to the orbital roof and inferior turbinate (site of attachment

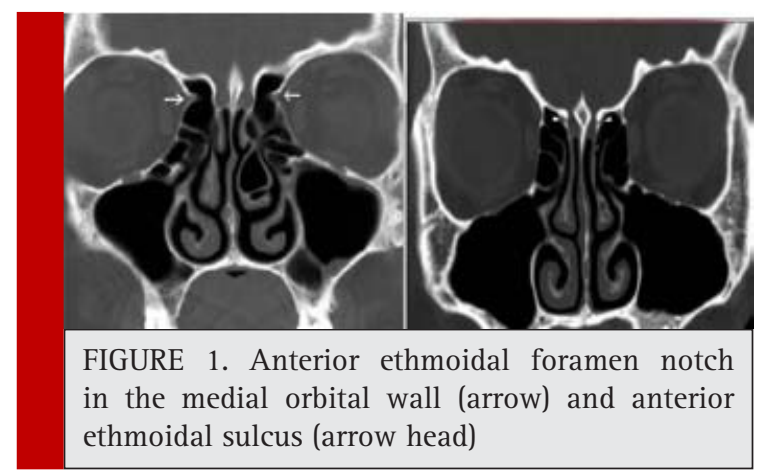




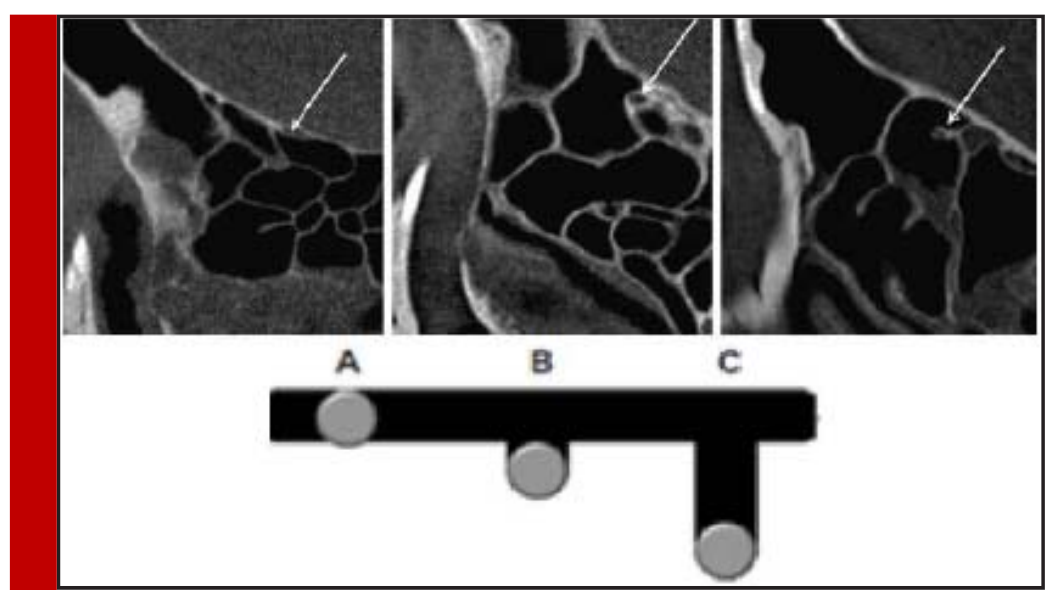

FIGURE 2. Location of the AEA on the sagittal plane (up). Schematic views (down): (A) Attached to the base of skull; (B) distance less than 1 $\mathrm{mm}$; (C) distance of $1 \mathrm{~mm}$ or more

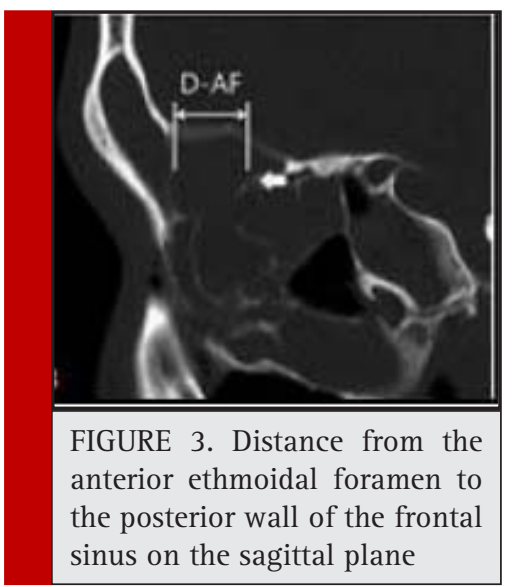

of bony lamella of inferior concha with medial wall of the maxillary sinus) in the coronal plane (Figure 4) was measured. To estimate the distance from the AEA to the nasion and also the distance from the AEA to the ANS, the oblique sagittal plane was used. In this plane, the angle between the hypothetical line connecting the AEA and ANS and horizontal line passing through the hard palate and ANS was measured (Monjas-Canovas et al. 2011) (Figure 5). Independent and paired t-test were used for statistical analyses. $\mathrm{P}<0.05$ was considered statistically significant.

\section{RESULTS AND DISCUSSION}

A total of 129 patients (59 males and 70 females) with a mean age of 41.59 years in males and 38.44 years in females were evaluated. Both sides were evaluated in each patient $(n=258)$. Independent t-test showed that the mean age of males and females was not significantly different $(\mathrm{P}=0.220)$. In most cases, the AEA was detect-

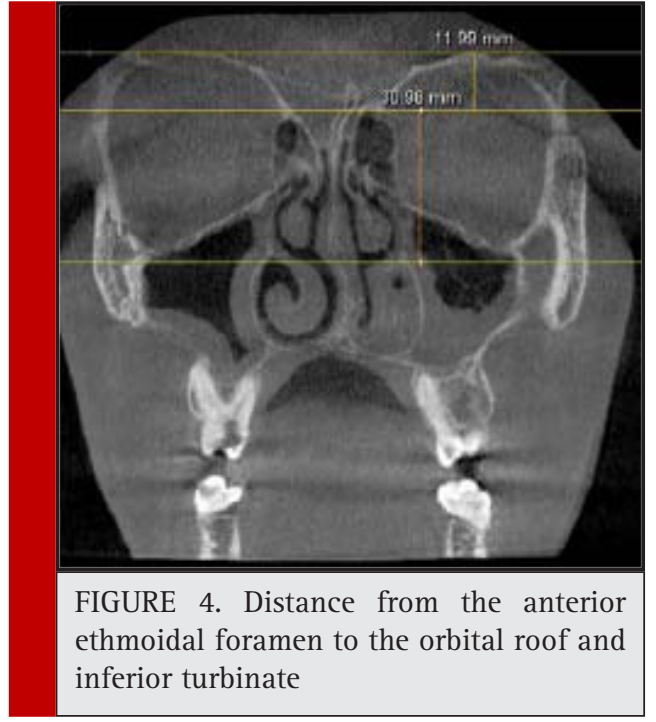

able on coronal sections of the anterior ethmoidal foramen in the medial wall of the orbit (96.1\%) in the form of a notch and anterior ethmoidal sulcus in the lateral wall of the olfactory fossa (94.2\%). The Fisher's exact test showed that the frequency distribution of presence of the AEA in the medial orbital wall and anterior ethmoidal sulcus was not significantly different in the right and left sides $(\mathrm{P}>0.05)$.The mean total distance from the AEA to the orbital roof on coronal sections was $11.60 \pm 1.94 \mathrm{~mm}$. This distance to the inferior turbinate was $32.66 \pm 4.33 \mathrm{~mm}$. As seen in Table 1, t-test showed no significant difference between the distance from the AEA to the orbital roof and to the inferior turbinate in the two sides $(\mathrm{P}>0.05)$. The mean distance from the AEA to the posterior frontal sinus wall $(8.96 \pm 4.51 \mathrm{~mm})$ and anterior base of the skull $(2.09 \pm 2.18 \mathrm{~mm})$ on sagittal sections is shown in Table 1; according to t-test, the differ- 


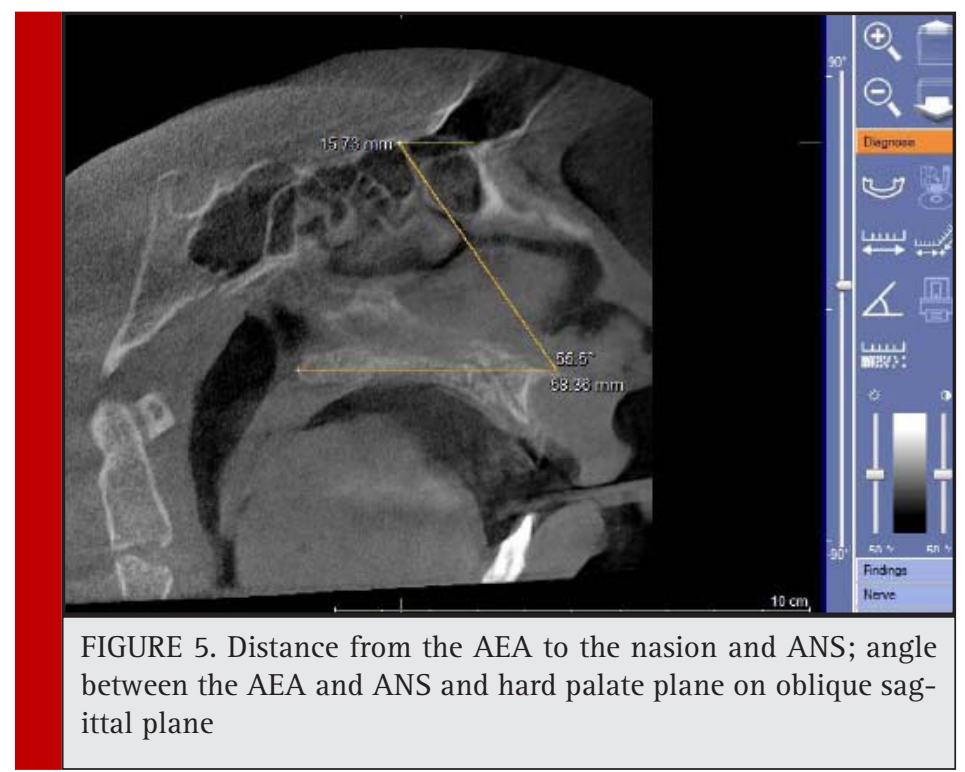

Table 1. Mean distance from the AEA to the orbital roof, inferior turbinate, posterior wall of the frontal sinus and anterior base of the skull in millimeters

\begin{tabular}{|l|c|c|c|c|}
\hline Distances & $\begin{array}{c}\text { Right (mean } \pm \text { SD) } \\
\mathrm{mm}\end{array}$ & $\begin{array}{c}\text { Left (mean } \pm \text { SD) } \\
\mathrm{mm}\end{array}$ & $\begin{array}{c}\text { Total (mean } \pm \text { SD) } \\
\text { Mm }\end{array}$ & P value \\
\hline Distance from AEA to orbital roof & $11.73 \pm 2.03$ & $11.48 \pm 1.85$ & $11.60 \pm 1.94$ & 0.13 \\
\hline $\begin{array}{l}\text { Distance from AEA to inferior } \\
\text { turbinate }\end{array}$ & $32.42 \pm 4.46$ & $32.90 \pm 4.21$ & $32.66 \pm 4.33$ & 0.20 \\
\hline $\begin{array}{l}\text { Distance from AEA to posterior } \\
\text { wall of frontal sinus }\end{array}$ & $8.66 \pm 4.46$ & $9.27 \pm 4.56$ & $8.96 \pm 4.51$ & 0.11 \\
\hline $\begin{array}{l}\text { Distance from AEA to anterior base } \\
\text { of skull }\end{array}$ & $2.10 \pm 2.27$ & $2.07 \pm 2.09$ & $2.09 \pm 2.18$ & 0.81 \\
\hline
\end{tabular}

ence in the mean distance from the AEA to the posterior wall of the frontal sinus and anterior base of the skull was not significant $(\mathrm{P}>0.05)$.

Table 2 shows the position of the AEA relative to the anterior base of the skull on sagittal CBCT sections based on the presented classification.

Table 3 shows the mean distance from the AEA relative to the nasion and ANS and angle of AEA relative to ANS in oblique sagittal plane. As seen in Table 3, according to paired t-test, no significant difference was noted in the mean variables in the right and left sides $(\mathrm{P}>0.05)$
As demonstrated in Table 4, independent t-test showed that the distance from the AEA to the orbital roof and inferior turbinate and distance from the AEA to the nasion and ANS in males were significantly greater than those in females $(\mathrm{P}<0.05)$ but no significant difference was noted between males and females in the AEA and ANS angle $(\mathrm{P}>0.05)$.

Many anatomical studies have assessed the location of the AEA and most of them used endoscopic measurements while some others used CT (Monjas-Canovas et al. 2012). On the other hand, studies on detection of AEA on CBCT scans are limited (Guldner et al. 2012).

\begin{tabular}{l} 
Table 2. Location of AEA relative to the anterior base of the skull on CBCT sagittal \\
sections in millimeters \\
\hline
\end{tabular}


Table 3. Mean distance from the AEA to the nasion, ANS and AEA-ANS angle on oblique sagittal plane

\begin{tabular}{|l|c|c|c|c|}
\hline & Right $\left(\mathrm{mean}_{ \pm} \mathrm{SD}\right)$ & Left $\left(\mathrm{mean}_{ \pm} \mathrm{SD}\right)$ & Total $\left(\mathrm{mean}_{ \pm} \mathrm{SD}\right)$ & P value \\
\hline $\begin{array}{l}\text { Distance between AEA } \\
\text { and nasion }\end{array}$ & $18.04 \pm 3.61 \mathrm{~mm}$ & $17.95 \pm 4.17 \mathrm{~mm}$ & $18.01 \pm 3.90 \mathrm{~mm}$ & 0.78 \\
\hline $\begin{array}{l}\text { Distance between AEA } \\
\text { and ANS }\end{array}$ & $58.58 \pm 4.09 \mathrm{~mm}$ & $58.81 \pm 4.40 \mathrm{~mm}$ & $58.69 \pm 4.24 \mathrm{~mm}$ & 0.21 \\
\hline $\begin{array}{l}\text { Angle between AEA and } \\
\text { ANS }\end{array}$ & $55.06 \pm 4.16^{\circ}$ & $55.24 \pm 4.56^{\circ}$ & $55.15 \pm 4.36^{\circ}$ & 0.53 \\
\hline
\end{tabular}

\begin{tabular}{|l|c|c|c|}
\hline \multicolumn{5}{|l|}{ Table 4. Mean and standard deviation of data based on gender } \\
\hline Distance & Female $\left(\right.$ mean $\left._{ \pm} \mathrm{SD}\right)$ & Male $\left(\mathrm{mean}_{ \pm} \mathrm{SD}\right)$ & P value \\
\hline Distance to orbital Roof & $11.97 \pm 1.80 \mathrm{~mm}$ & $11.17 \pm 2.01 \mathrm{~mm}$ & 0.001 \\
\hline Distance to inferior turbinate & $31.51 \pm 4.27 \mathrm{~mm}$ & $34.03 \pm 4.02 \mathrm{~mm}$ & 0.000 \\
\hline $\begin{array}{l}\text { Distance to anterior base of } \\
\text { skull }\end{array}$ & $2.17 \pm 2.12 \mathrm{~mm}$ & $1.99 \pm 2.25 \mathrm{~mm}$ & 0.50 \\
\hline $\begin{array}{l}\text { Distance to inferior wall of } \\
\text { frontal sinus }\end{array}$ & $8.56 \pm 3.83 \mathrm{~mm}$ & $9.44 \pm 5.18 \mathrm{~mm}$ & 0.132 \\
\hline Distance to nasion & $17.25 \pm 3.28 \mathrm{~mm}$ & $18.91 \pm 4.38 \mathrm{~mm}$ & 0.01 \\
\hline Distance to ANS & $56.46 \pm 3.33 \mathrm{~mm}$ & $61.33 \pm 3.66 \mathrm{~mm}$ & 0.00 \\
\hline Angle between AEA and ANS & $55.44 \pm 4.06^{\circ}$ & $54.79 \pm 4.69^{\circ}$ & 0.23 \\
\hline
\end{tabular}

The AEA passes through three cavities namely the orbit, the ethmoidal labyrinth and the anterior cranial fossa. The AEA enters into the olfactory fossa from the anterior cranial base and then enters into the anterior ethmoidal sulcus through the lateral lamella of the cribriform plate, which is the weakest point of the anterior base of the skull. At this point, bone is dangerously thin and it is considered a high-risk area in nasal endoscopic surgery. Thus, the AEA is susceptible to traumatization and injury during surgical procedures (Stammberger et al. 1990; Bayram et al. 2001; Moon et al. 2001; White et al. 2005; Araujo Filho et al. 2006; Souza et al. 2009).

In most cases in our study, this artery was detectable in the medial wall of the orbit (96.1\%) and lateral wall of the olfactory fossa (94.2\%). Similarly, Souza et al. detected AEA in the medial orbital wall (98\%) and lateral wall of the olfactory fossa (100\%) and stated that medial notch of the orbit and medial ethmoidal sulcus were reliable landmarks for detection of the AEA (Souza et al. 2009). Gotwald et al, similarly detected the orbital medial notch on coronal CT scans in 95\% and medial ethmoidal sulcus in 84\% of cases (Gotwald et al. 2004). Ding et al. used CT angiography and detected AEA in $100 \%$ of the cases in the notch in the medial orbital wall and in 98.4\% in the ethmoidal sulcus (Ding et al. 2012). Considering the invasiveness of CT angiography and high dose of CT, low dose CBCT is more suitable for detection of AEA. In FESS, superior lateral border of the surgical site is determined based on the location of AEA and the inferior border is determined by the inferior tur- binate (Rontal et al. 1991). Distance from the AEA to the attachment site of the inferior turbinate determines the suitable location for surgical procedure. Basak et al. considered the orbit as a fixed reference point and based on this point, they determined the location of AEA. The mean distance from the AEA to the orbital roof on CT scans was reported to be $13.7 \mathrm{~mm}$ (Basak et al. 1998) while in our study, this distance was found to be $11.60 \pm 1.94 \mathrm{~mm}$. Basak et al. measured the mean distance from the AEA to the inferior turbinate to be $30.05 \mathrm{~mm}$ (Basak et al. 1998) and Eren et al. found this distance to be $31.6 \mathrm{~mm}$ on CT scans (Eren et al. 2016); these values were close to our findings ( $32.66 \pm 4.33 \mathrm{~mm})$.

The distance from the AEA to the skull base is important because when AEA with mesenterium is located right beneath the skull, it has higher risk of traumatization during surgery. Basak et al. evaluated the location of AEA on coronal CT scans and reported that it was adjacent to the skull base in 57\% of the cases and had a distance from it in $43 \%$. In cases where AEA has a distance from the base of skull, risk of traumatization during FESS is higher (Basak et al. 1998). Moon et al. assessed both sagittal sections and cadaver dissection and reported that in $85.7 \%$ of cases, AEA was adjacent to the skull base; in the remaining cases, AEA had 2-3 $\mathrm{mm}$ distance from the skull base (Moon et al. 2001). Guldner et al. (2012) reported similar results. Araujo et al. reported that AEA was attached to the skull base in 83.3\% of the cases (Araujo Filho et al. 2006). Kainz and Stammberger reported that in most cases, AEA had 5 
mm distance from the skull base. They also stated that when the roof of ethmoidal sinus is low, anterior ethmoidal canal may be attached to the skull base (Kainz et al. 1988). The same was stated by Becker et al, who determined the location of foramen in endoscopic sections. Jang et al. reported this distance to be $1.32 \pm 1.51 \mathrm{~mm}$ on CT scans (Jang et al. 2014) while in our study, this distance was $2.09 \pm 2.18 \mathrm{~mm}$. These differences may be due to racial differences or surgical technique. It seems that in patients with larger supraorbital ethmoid cell and optimal pneumatization of ethmoidal sinus (Jang et al. 2014), AEA is located right beneath the skull base; otherwise, it is at the same level of the skull base (Lisbona et al. 2010).

Young et al, in their study measured the distance from the AEA to the base of skull and categorized it in three groups of no distance [16\%], distance less than 1 $\mathrm{mm}(33.7 \%)$ and equal or higher than $1 \mathrm{~mm}$ (50.5\%) (Ko et al. 2014). In our study, $41.9 \%$ were categorized in no distance group, 1.2\% were categorized in less than $1 \mathrm{~mm}$ group and 57\% were categorized in $1 \mathrm{~mm}$ and higher group. In most cases in both studies, the distance from the AEA to the skull base was equal or more than $1 \mathrm{~mm}$.

Frontal sinus is the most challenging sinus in endoscopic surgery due to its anatomical complexity and variations. Many studies have suggested anatomical landmarks to help the surgeon in safe conduction of frontal sinus surgery (McLaughlin et a;. 1997; Lee et al. 1997; Kew et al. 2002). The AEA is known as a typical classic reference point for the frontal sinus. Some studies showed that AEA is located right behind the frontal recess and can serve as an anatomical landmark for frontal sinus surgery (White et al. 2005). Thus, knowledge about the anatomy of this area is important and must be obtained prior to endoscopic sinus surgery. Young et al. reported the mean distance from the AEA to the posterior wall of the frontal sinus to be 8.58 \pm 5.56 $\mathrm{mm}$, which was in line with our result $(8.96 \pm 4.51 \mathrm{~mm})$; whereas, Jang et al. measured the distance from the AEA to the anterior wall of the frontal sinus to be $17.36 \pm 2.19$ $\mathrm{mm}$ [19]; this difference was due to the different reference points selected. Statistically, similar to our study, Young et al. found no significant association between the distance from the AEA to the frontal sinus and AEA to the base of skull (Ko et al. 2014).

In endoscopic surgery of the sinus, zero degree ANS angle complicates the detection of AEA [9]. Donemez et al. considered ANS as a fixed landmark and measured its distance from the AEA on cadavers using an electronic caliper, and reported the value to be $55 \pm 3 \mathrm{~mm}$ (Donmez et al. 2005). However, Monjas-Cánovas et al. measured the distance from the AEA to ANS to be $55.51 \pm 5.52 \mathrm{~mm}$ and measured its angle with the horizontal line passing through the ANS to be $57.7 \pm 1.78^{\circ}$; these values were close to those of Moon et al.(2001), Lee et al. (2000) and Araujo et al. (2006). Our study reported this distance to be $58.69 \pm 4.26 \mathrm{~mm}$ and the angle was $55.14 \pm 4.37^{\circ}$, which was in line with previous studies. Araujo et al. (2014) reported that the distance from the AEA to ANS was significantly greater in males than in females; this difference was not statistically significant in our study and that of Lee et al. (2000).

Nasion is used as a reference point in CT scan studies for surgical resection of some tumors or management of uncontrollable arterial hemorrhage, which is endoscopically impossible; although external incision is made from the canthus and not directly on the nasion. Monjas-Cánovas et al. measured the mean distance from the AEA to the nasion to be $29.31 \pm 2.5 \mathrm{~mm}$ (2011), which is similar to the study by Cankal et al. (2004); whereas, the results of Eren et al. (2014)(17.99 \pm 3.91$)$ were closer to ours $(18.01 \pm 3.90 \mathrm{~mm})$. In our study, a weak but significant association was noted between the distance from the AEA to the ANS and the distance from the AEA to the nasion; whereas, Eren et al. (2014) found a significant association between the distance from the AEA to the nasion and the distance from the AEA to the inferior turbinate (Eren et al. 2014).

\section{CONCLUSION}

Inadequate knowledge about the anatomy of surgical site can cause serious iatrogenic surgical complications. To decrease these risks, a careful dissection must be done after thorough assessment of the area on CBCT scans. Therefore, adequate knowledge about the anatomy of the area and location of the AEA by use of CBCT can be helpful prior to FESS.

\section{REFERENCES}

Araujo Filho BC, Weber R, Pinheiro Neto CD, Lessa MM, Voegels RL, Butugan 0. (2006) Endoscopic anatomy of the anterior ethmoidal artery: a cadaveric dissection study. Braz J Otorhinolaryngol 72(3):303-8.

Basak S, Karaman CZ, Akdilli A, Mutlu C, Odabasi 0, Erpek G. (1998) Evaluation of some important anatomical variations and dangerous areas of the paranasal sinuses by CT for safer endonasal surgery. Rhinology 36(4):162-7.

Bayram M, Sirikci A, Bayazit YA. (2001) Important anatomic variations of the sinonasal anatomy in light of endoscopic surgery: a pictorial review. Eur Radiol 11(10):1991-7.

Becker SP. (1994) Applied anatomy of the paranasal sinuses with e9mphasis on endoscopic surgery. The Annals of otology, rhinology \&t laryngology Supplement 162:3

Cankal F, Apaydin N, Acar HI, Elhan A, Tekdemir I, Yurdakul $\mathrm{M}$, et al. (2004) Evaluation of the anterior and posterior 
ethmoidal canal by computed tomography. Clinical radiology 59(11):1034-40.

Ding j, Sun G, Lu Y, Yu B-b, Li M, Li L, et al. (2012) Evaluation of Anterior Ethmoidal Artery by 320-Slice CT Angiography with Comparison to Three-Dimensional Spin Digital Subtraction Angiography . Initial Experiences, Korean J Radiol 13(6):667-73.

Donmez BO, Agirdir BV, Sindel MM. (2005) Important anatomical landmarks in the lateral nasal wall. Saudi medical journal 26(9):1403-8.

Eren E, Altay C, Arslanoglu S, Erdogan NK, Uluc ME, Onal K, et al. (2014) Searching for the cheese: does ethmoid pneumatization affect the location of the anterior ethmoid artery? EUFOS : affiliated with the German Society for Oto-Rhino-Laryngology - Head and Neck Surgery 271(2):281-5.

Gotwald TF, Menzler A, Beauchamp NJ, zur Nedden D, Zinreich SJ. (2003) Paranasal and orbital anatomy revisited: identification of the ethmoid arteries on coronal CT scans. Critical reviews in computed tomography 44(5):263-78.

Guldner C, P.Zimmermann A, Diogo I, Werner JA, Teymoortash A. (2012) Age-dependent differences of the anterior skull base. International Journal of Pediatric Otorhinolaryngology 76:822-8.

Jang DW, Lachanas VA, White LC, Kountakis SE. (2014) Supraorbital ethmoid cell: a consistent landmark for endoscopic identification of the anterior ethmoidal artery. Otolaryngology-head and neck surgery : official journal of American Academy of Otolaryngology-Head and Neck Surgery 151(6):1073-7.

Kainz J, Stammberger H. (1988) The roof of the anterior ethmoid: a locus minoris resistentiae in the skull base. Laryngologie, Rhinologie, Otologie 67(4):142-9.

Kew J, Rees GL, Close D, Sdralis T, Sebben RA, Wormald PJ. (2002) Multiplanar reconstructed computed tomography images improves depiction and understanding of the anatomy of the frontal sinus and recess. American journal of rhinology 16(2):119-23.

Ko Y-B, Kim M-g, Jung YG. (2014) Anatomical Relationship between the Anterior Ethmoid Artery, Frontal Sinus, and Intervening Air Cells ; Can the Artery Be Useful Landmark? Korean J Otorhinolaryngol-Head Neck 57(10):687-91.
Lee D, Brody R, Har-El G. (1997) Frontal sinus outflow anatomy. American journal of rhinology 11(4): 283- 5.

Lee WC, Ming Ku PK, van Hasselt CA. (2000) New guidelines for endoscopic localization of the anterior ethmoidal artery: a cadaveric study. Laryngoscope 110(7):1173-8.

Lisbona Alquezar MP, Fernandez Liesa R, Lorente Munoz A, Perez Delgado L, Herrera Tolosana S, Tejero-Garces Galve G, et al. (2010) Anterior ethmoidal artery at ethmoidal labyrinth: Bibliographical review of anatomical variants and references for endoscopic surgery. Acta Otorrinolaringol Esp 61(3):202-8.

McLaughlin RB, Jr., Rehl RM, Lanza DC. (2001) Clinically relevant frontal sinus anatomy and physiology. Otolaryngologic clinics of North America 34(1):1-22.

Monjas-Canovas I, Garcia-Garrigos E, Arenas-Jimenez JJ, Abarca-Olivas J, Sanchez-Del Campo F, Gras-Albert JR. (2011) Radiological anatomy of the ethmoidal arteries: CT cadaver study. Acta Otorrinolaringol Esp 62(5):367-74.

Monjas-Cánovas I, García-Garrigós E, Arenas-Jiménez JJ, Abarca-Olivas J, Campo Fs-D, Gras-Alberta JR. Radiological Anatomy of the Ethmoidal Arteries: CT Cadaver Study. Acta Otorrinolaringol Esp 2011;62(5):367-74.

Moon HJ, Kim HU, Lee JG, Chung IH, Yoon JH. (2001) Surgical anatomy of the anterior ethmoidal canal in ethmoid roof. Laryngoscope 111(5):900-4.

Rontal M, Rontal E. (1991) Studying whole-mounted sections of the paranasal sinuses to understand the complications of endoscopic sinus surgery. The Laryngoscope 101(4 Pt 1):361-6.

Rontal M, Rontal E. (1991) Studying whole-mounted sections of the paranasal sinuses to understand the complications of endoscopic sinus surgery. The Laryngoscope 101(4 Pt 1):361-6.

Souza SA, Souza MMAd, Gregório LC, Ajzen S. (2009) Anterior Ethmoidal Artery Evaluation on Coronal CT Scans. . Braz J Otorhinolaryngol 101-6(1):101-6.

Stammberger H, Posawetz W. (1990) Functional endoscopic sinus surgery. Concept, indications and results of the Messerklinger technique. EUFOS : affiliated with the German Society for Oto-Rhino-Laryngology - Head and Neck Surgery 247(2):63-76.

White DV, Sincoff EH, Abdulrauf SI. (2005) Anterior ethmoidal artery: microsurgical anatomy and technical considerations. Neurosurgery 56(2 Suppl):406-1. 